\title{
DEEPENING CONDITIONS OF PRECARITY IN THE KOREAN GAME INDUSTRY AND COLLABORATIVE STRATEGIES TO OVERCOME CONSTRAINTS
}

\author{
Sangkyu Lee \\ Korea Culture \& Tourism Institute \\ postdoal@gmail.com
}

\begin{abstract}
This paper examines how Korean game developers have been experiencing deepening conditions of precarity and makes a few suggestions regarding how they could overcome their structural limitations. Despite the remarkable growth in the Korean game industry, many underlying problems overshadow its success, such as labor exploitation, low wages, employment instability, and alienated labor. This paper uses a qualitative methodology to investigate the implications of the game industry market's transition from PC online to the mobile game platform since the 2010s, which contributed to the industry's deteriorating working condition and production system. Given this context, this study explores how the game developers experienced deepening conditions of precarity. This paper offers a few suggestions about overcoming these structural constraints. First, game developers can appropriate their know-how and resources then integrate them into a new form of "digital creative labor," which refers to networked and collaborative cultural practices of game developers. Secondly, this paper argues that the intervention at the institutional and policy level is necessary to protect the rights and interests of workers.
\end{abstract}

\section{Keywords}

digital creative work; game developer; Korean game industry; networked creative collaboration; precarity

\section{About the Author}

Sangkyu Lee is a researcher at the Content Industry \& Economy Research Center of Korea Culture \& Tourism Institute (KCTI). He is also a lecturer and tutor in the Graduate School of Media Arts and Cultural Contents, Korea National Open University (KNOU). He was a former research assistant in Seoul National University (SNU) Asia Center and Department of Communication. His main fields of research are the Korean contents industry and popular culture. He is interested in the change of media technology, production process, and the condition of labor in contemporary creative industries. 


\section{INTRODUCTION: EXPLORING THE PRECARITY AND COMPETENCY OF KOREAN GAME DEVELOPERS}

As a creative industry, what kinds of production processes and working culture have been formed in the Korean game industry? As digital creative workers, how do game developers cope with the structural precariousness they face? This study will answer these questions.

This study particularly focuses on developers in the Korean game industry. The game industry is at the cutting edge of the ICT industry in this era, and it is the field of high technology that is most sensitive to changes in technology and software. It is also a field where the interrelationship between technology and labor dramatically appears. It is characterized by systemic and creative collaborations by workers in various disciplines such as game design, graphic art, and programming. Also, the game industry is a typical labor-intensive field that can generate a highvalue product from "manpower" only, so it is essential to understand the working environment and the development process of the game industry. By closely examining them, we can understand the characteristics of the game production process, its limitations, and possibilities. Then we can expand our understanding of creative industries to other fields like movies, broadcasting, animation, and music.

The Korean game industry has soared over the past thirty years and still has been growing by the year 2017 with a market size of about 11 trillion won (KRW) (KOCAA, Contents Industry Outlook 2018 34). However, there are also many problems like exploitation of labor, low wages, employment instability, and alienated labor that game developers are experiencing. This study conceptualizes this situation as "precarity" and interprets that the precarity of developers is "deepening" especially in the context of contemporary Korean game industry, especially after the 2010 .

Keeping in mind these contexts, this paper raises two central research questions. First, how has game developers' precarity been deepened in the structural changes of the Korean game industry? In particular, this paper will examine the background of the transition of the main market of the game industry from PC online to mobile game platform since the 2010s, and explore how the precarity of game developers deepens in such environments. Here, precarity is divided into five categories: precarity in employment, career, economic condition, work-life balance, and alienated labor due to an excessive division of labor or de-skilling.

Second, how can Korean game developers overcome these structural limitations? In this regard, the study seeks two strategies. The first way is for game developers to appropriate the know-how and resources they have accumulated in their working process. For example, they could actively adapt software tools for new platforms 
in game production, or independently perform their converged work away from fragmented passive labor, using the networks and subcultural capital that developers have naturally built. There exist potential and possibilities for forming alternative creativity, expertise, and skills through multi-skilled, networked creative collaboration. This could be understood through the concept of "digital creative labor" proposed in this study.

Another strategy can be implemented at the institutional and policy level. Specifically, legislative and institutional systems to protect the rights and interests of workers can be developed. In this way, we can reform and improve existing labor practices that encourage overtime work at low wages. In the long term, various supporting policies are needed to construct a sustainable game industry ecosystem by strengthening the potential competency of game developers for digital creative work and reinforcing their negotiating power in the labor market. These strategies could also ensure the game developer's autonomy, independence, and creativity.

To answer these questions, this study conducted qualitative research on Korean game developers and their working sites. First, it conducted in-depth interviews with forty-two developers with a variety of backgrounds coming from a large game studio to a small development team. Participants include game designers, artists, programmers, project directors (PD), project managers (PM), quality assurance (QA) and customer service (CS) staffs. Second, the research conducted participant observation on the game company and studio for about two months. Third, the researcher participated in various game developers' conferences and seminars held in Korea to collect on-site records and data. In addition, this study analyzed business reports, white papers about Korean game industry, and related literature data.

The purpose of this study lies beyond merely understanding the reality of Korean game workers. Ultimately, this study attempts to investigate the structural limitations and possibilities of labor in the broader field of the creative industry in Korea, of which the game industry is a prime example.

\section{LITERATURE REVIEW AND THEORETICAL BACKGROUND}

\section{A. Previous Studies on the Labor of the Game Industry}

The creative industry encompasses various cultural industry sectors including movie, TV, music, and games, and produces the latest trends and cultural codes, which evokes an exciting, cool, artistic, and young image. The labor in the creative 
industry can be understood as creating products and services with symbolic value through aesthetic, expressive, attractive and communicative forms of work (Hesmondhalgh and Baker), which provides opportunities for individual creativity, autonomy, enthusiasm, and self-realization. On the other hand, labor in creative industries is very flexible and unstable. Most of the creative workers are doing project-based, freelance work. Thus, it is very challenging to plan a stable career and to predict the sustainable future. In this context, many scholars have continuously raised the problems of labor instability and the risk of self-exploitation in creative industries (Ursell; Deuze; Park; Jung). The following sections identify what has been mainly discussed about the labor of the game industry in these previous studies.

\section{The Working Culture of Game Developers}

In the process of core game production, there are three major disciplines: designers, graphic artists, and programmers. Game designers construct the virtual world, story, and concept of the game, while graphic artists are responsible for the artistic expressions and design of the characters and the background. Game programmers or engineers make codes for programming, by utilizing game engines and software tools. Besides, there are PDs and PMs who lead the game development team and make decisions, QA staffs who conduct various tests after the game, as well as workers in game management (GM) or CS parts who provide customer service and maintenance tasks of the game in service. In the game development process, it is crucial that these various people show their expertise while they are harmonized as a whole. Game development studios also emphasize the ability to manage potential colleagues, to form social networks and to perform active communications (Deuze; O’Donnell).

In general, the culture of game development organizations tends to be horizontal, flexible, and autonomous. A freewheeling, Bohemian lifestyle for game workers is widely allowed or even encouraged in game companies. They can wear jeans, T-shirts, short pants with slippers in offices. Most game companies adopt workplace policies that encourage free expression of personalities in order to make their working environment more creative and fun, for instance by providing snacks such as beer or pizza for free during working hours or by offering relaxation spaces which reminds one of the atmosphere of college campuses (DyerWitheford and de Peuter). Another feature of the game development culture is that the boundaries between professional game developers and users are not so clear, and users (also fans) can participate in game production in various ways such as making modifications or variations of the original game (Postigo; Arakji and Lang). Furthermore, the concept of work in this environment is often characterized by the tendency of "labor as a play (playbor)" due to the disappearance of the boundary between work and play (Bulut 2). 


\section{Issues Surrounding the Working Environment}

There is a distinctive habitual labor practice in the game industry, called "crunch mode." This refers to a period of intensive night-time and overtime work, especially in times of a critical emergency such as on the date of the game release or update. Due to the inherent limitations of the game industry, such as a very short project duration and low probability of success, there are a myriad of unexpected variables in the game production process, resulting in a number of risks in terms of scheduling and manpower management (Dyer-Witheford and de Peuter; Kerr; Peticca-Harris et al.). Excessive exploitation of labor is a common way that companies choose to overcome this underlying uncertainty. Recently in Korea, there have been serious criticisms of the excessive exploitation and poor working conditions of these workers, drawing social attention to problems such as delay in wage payment and illegal overwork. With the increasing labor flexibility in the game industry, the developers' job instability and precarity have worsened. To make matters worse, various legal constraints and heterogeneity of game developers make it profoundly challenging to organize labor unions in the game industry. As Thompson et al. shows, workers in game development studios play a minimal role since they have little chance to show their autonomy and creativity, which could aggravate alienated labor. The above reasons have hindered the fundamental solution to this problem (Teipen; Legault and Weststar).

In sum, previous studies on the labor of the game industry show some positive aspects such as collaboration, horizontal communication, and participatory culture. On the other hand, critical issues have been raised regarding the poor working environment and exploitation of labor. Still, few studies have taken into account the specific socio-economical context of the industry focusing in detail on precarity of the game developers in the labor process and how such problems have become worse. There is also a lack of discussion on what actions or countermeasures are needed to overcome those problems. This study focuses on the mobile game industry in Korea since 2010 and explores in-depth interviews with game developers, asking how precarity has been deepened in game industry labor. This study also tries to find out the potential possibilities and strategies to overcome those limitations.

\section{B. Theoretical Background}

1. The Precarity of the Game Industry Workers 
The term "precarity" or "precarious" originated from the 1970-80s Italian labor movement called "Operaismo" (Workerism). Since the 20oos, it has been used as a concept which refers to the unstable and vulnerable state of irregular workers, freelance artists, and young people who suffer from harsh working conditions in the extremely flexible labor market (Standing; Chae).

This paper investigates the unstable situation of game workers by focusing on the concept of precarity. Here, precarity is a concept that includes insecurity and vulnerability, destabilization and endangerment, but it does not just mean the general instability or uncertainty of the labor market, such as job insecurity, low wages, and exclusion from social security systems. Precarity implies existential weaknesses, including emotional difficulties, such as the sense of alienation and emptiness of workers who cannot demonstrate sufficient autonomy and creativity in their labor. It also implies that the issue of precarity is not universally applicable, but rather that it is linked to discrimination, social exclusion of disadvantaged people, and gaps in the inequality of structure, which is undergirded by a differentiated allocation of resources and power (Butler 25-26). ${ }^{1}$

In this regard, we can refer to the discussion of Isabell Lorey, who reinterprets the theory of Butler and Foucault, to explain the problem of precarity as a form of "biological governmentality" in the neoliberal era (Lorey, State of Insecurity: Government of the Precarious). Neoliberal governmentality operates regulatory power through continuous "precarization" or "normalization of Precarity" As fragmented individuals, the working subjects are required to internalize the ethics of self-governing and to solve the risks and burdens of precarization in an individualized way. ${ }^{2}$ The problem is that in this situation, people take the precondition of precarity as a natural condition and force themselves to cope with the problems derived from it without borrowing the power of any social solidarity or community, thereby creating a self-precarization (Lorey 44). ${ }^{3}$

This concept is particularly useful in understanding the contradictory conditions of creative workers such as game developers. Ross named newly arising professionals of American new media industry as "no-collar," distinguished from blue-collar or white-collar workers (Ross 33). They are characterized by the pursuit of Bohemian values and relative independence from existing cultural customs. They usually oppose established authority and form a working culture that emphasizes the value of sharing, cooperation, communication, and autonomous self-management. ${ }^{4}$ Having competency to adapt in the flexible IT industry, they pursue freewheeling lives like wanderers, demonstrate their passion and personality through work, and combine their work with life. For these reasons, they were regarded as representative workers of the New Economy. However, they did not pay much attention to poor working conditions such as long hours of work and low 
wages because of their weak identity as "workers," and just insisted on autonomous control of work, flexibility, and a liberal workplace culture. Ironically, Ross argued that this situation puts them at risk of being constantly exploited.

Even though the workers of the digital creative industry have potential and capacity, they are prone to be in contradictory situations because they can also become more vulnerable and unstable. Moreover, the probability of success is extremely low in this business, so that there is a huge gap between successful and unsuccessful people. So the concept of precarity can capture these distinctive characteristics of labor in the creative industry like the game industry.

In addition, as we have seen in the literature review, the game industry's typical overtime, concentrated labor practices, represented by "crunch mode," shows that the problem of exploitation and alienated labor still exists today in the game industry. Those were the typical problems of early industrial capitalism, but they still matters these days. It is also linked to the problem of de-skilling or degradation of labor (Braverman) due to technological development including commercial game engines, the excessive division of labor, and standardized development processes. Based on these discussions, this study re-conceptualizes the precarity of game workers as problems of sophisticated exploitation mechanisms in the neoliberal era that are combined and overlaps with that of traditional industrial capitalism which involved alienated labor, de-skilling, and forced exploitation. As a result, game workers are at the risk of a twofold danger in the contemporary structure of the game industry.

\section{Digital Creative Work: Potential Competency to Overcome Precarity}

This study critically engages with existing theories of creative labor, immaterial labor, and digital labor. Based on a dialectical synthesis of these concepts, it suggests a new concept of "digital creative work" that implies the possibility to overcome precarity through dialectical synthesis.

The previous studies on creative labor explained the unique characteristics of workers in creative industries, distinguished from existing manufacturing or service industries, in that they seek values and meanings from labor by pursuing creativity, self-fulfillment, and self-realization dreams (Hesondhalgh and Baker; Ross; An). However, there are some limitations of these studies that did not fully take into account the new technology and digital environment and did not discuss critically how it changes the form of labor in the workplace. 
Theories of immaterial labor well explain the macroscopic changes in labor. In the discussion of Lazzarato, Negri and Hardt, and Fuchs ("Labor in Informational Capitalism"), immaterial labor is the labor which produces not only something intellectual, informal, cultural but also communicative and affective. Specifically, it provides services such as education, social relations, emotional sympathy, and caring, as well as cultural products like movies, music, and games, using computer technology and networks. Immaterial labor creates opportunities for communication and cooperation between producers and consumers, which is explained as the hegemonic production pattern of this era, resulting not only in changes in the form of labor but also in social relationships and daily life. However, as these studies were limited in a macroscopic view, the concept of immaterial labor has not been able to deal with concrete issues such as how precarity of labor has deepened in specific working conditions.

Meanwhile, theories of digital labor have insightfully pointed out that the everyday media use of audiences is changing into labor which produces economic value and that the border between producers and consumers is disappearing (Terranova; Scholz; Fuchs, Digital Labour and Karl Marx). In other words, the users' free Internet search or SNS activity itself acts like unpaid labor, giving emergence to a new form of exploitation. This explanation comes from a critical and pessimistic viewpoint. However, with the concept of "convergence culture," Jenkins insists that media users are able to actively transform cultural goods, appropriately utilize various technological resources such as networks, devices, and platforms. Jenkins maintains an optimistic view on the process of participating in the production process.

This study critically synthesizes existing theories and suggests the concept of digital creative work that implies the potential competency of game developers to cope with and overcome their precarity. This concept could be defined as the work of creating digital cultural contents through convergence and creative collaboration performed by networked, autonomous workers in digital technology environment of creative industries. This concept could be distinguished from traditional analog manufacturing or performance of artists due to the following features. First, digital creative work is a process of producing digital content and interacts closely with high-tech environments such as digital technology, network, and platforms. For example, digital creative work can adopt the dissemination of commercial game engines such as Unity and Unreal and the evolution of software production tools. Second, digital creative work is an autonomous, artistic, innovative work that pursues creativity. Third, it aims to become "work" which is distinguished from "labor." According to Hanna Arendt, labor, which has a negative meaning of suffering and trouble, and work, that implies the positive meaning of worldcreating activity, can be conceptually distinguished..$^{5}$ If "labor" means simply 
doing given fragmented tasks repetitively under a labor division system, it can be understood that digital creative workers like game developers are pursuing creative and autonomous "work." This concept also implies control over the entire work process of traditional artisanal work and the possibility of communicative, cooperative work or collaboration (Fuchs and Sevignani). Fourth, digital creative workers are multi-faceted and contradictory. They may be artistic bohemians but also have pioneering expertise in cutting-edge technology, as well as cultural entrepreneurship. On the other hand, however, they are also precarious laborers who are at the same time vulnerable to exploitation in harsh working conditions. They strive to accumulate the potential and know-how provided by positive experiences of digital creative work to overcome such structural limitations.

To summarize, the concept of digital creative work is useful for understanding the potential of game developers to overcome structural constraints since it implies creative competence, autonomy, ethics, culture, and unique subjectivity of workers in creative industries. For example, game developers who practice digital creative work can take advantage of the technological environment in a form of small start-ups and single-person development. They can actively involve all the stages of game production including planning, designing, programming, release and distribution, which means they can overcome the division system of labor that can cause de-skilling or alienated labor. Through "converged work" or "networked creative collaboration" (which are manifestations of digital creative work), they can acquire control on their own work and share their ideas and resources with other fellow developers, as well as game users, and co-produce the game.

\section{Methodology and Analytical Framework}

As previously mentioned, methodologically, this study adopts a qualitative method based on in-depth interviews with forty-two game developers and participation observations. ${ }^{6}$ The interview questions focused on the interviewees' general perception of the Korean game industry, including the working conditions, the process of game development, and their thoughts and feelings about work. In the course of this process, first of all, the background and elements contributing to the precarious working condition such as unstable career, low income, overwork, and problems of alienated labor were extensively analyzed. It helped the researcher to better understand how their precarious condition of labor has been exacerbated. Second, it explored what the interviewees' strategies were to confront the structural limitations such as by using their own technological know-how and networks of collaboration. In addition to analyzing the interview data, by conducting participant observation on their workplaces, the researcher examined their work process more 
in detail. On top of the data about teKorean game industry, labor environment and discourses on game developers were also analyzed.

The analytical framework of the main subject is set in three aspects as follows.

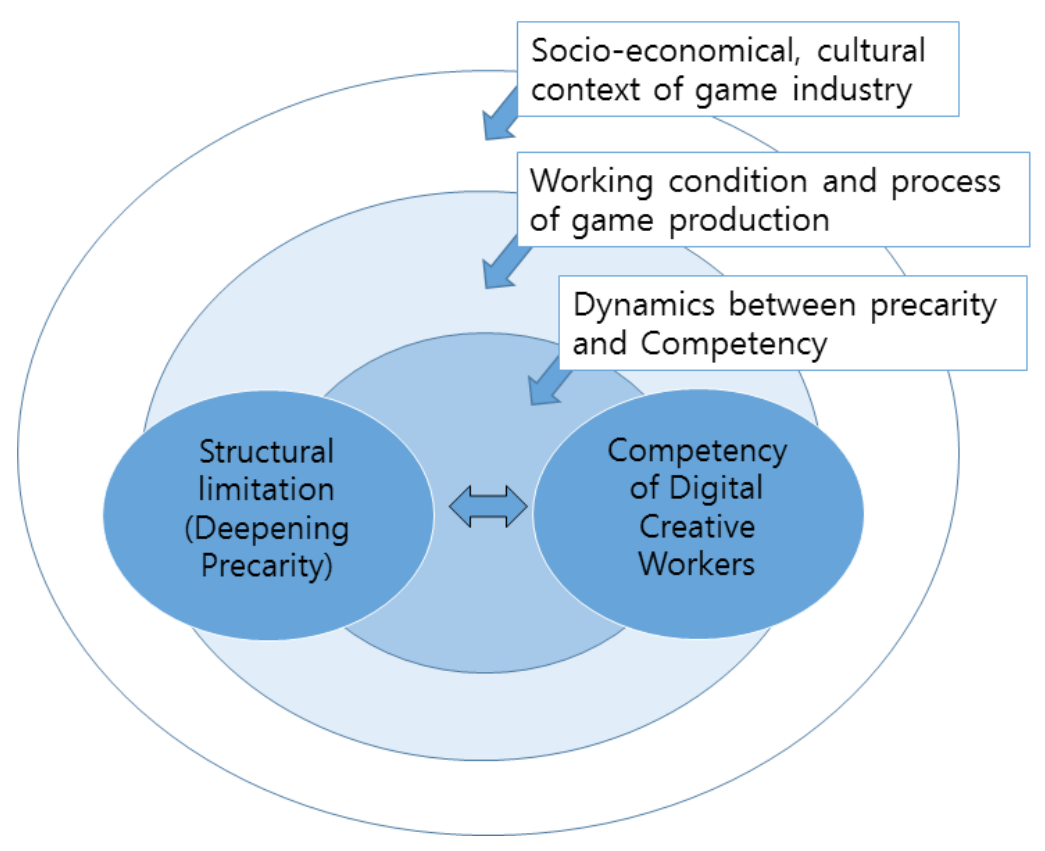

Figure 1. Analytical Framework of the Study

First, this study analyzed how the production environment of the Korean game industry has changed since the 2010s, considering the socio-economic and cultural context. Second, it examined the characteristics of the working conditions and game development processes in that context. Particularly, it analyzed how precarity of game developers' labor has been intensified. Third step was to analyze the dynamics between structural limitations and competencies of digital creative workers in the ground level. To clarify that dynamics, it examined how Korean game developers were actually experiencing precarity within the structural limitation. At the same time, it also investigated the ways of overcoming those limitations through the positive potential of digital creative work. In section 3, we will look closely at the structural changes in the Korean game industry and the characteristics of deepening precarity, and in section 4 , the possibility and strategies to overcome its structural limitations will be discussed. 


\section{CHANGES IN PRODUCTION ENVIRONMENT AND DEEPENED PRECARITY OF KOREAN GAME DEVELOPERS}

\section{A. Structural Problems and Issues in the Korean Game Industry}

According to the White Paper on Korean Games 2017, the market size of the Korean game industry is about 10.894 trillion won (about US\$ 1,012.9 million) in 2016, occupying 5.7 percent of the world market after the US, China, Japan and the UK. In particular, the online game market is ranked second in the world and the mobile game market is the fourth largest in the world. On average, it is the world's fifth largest game industry. In terms of PC online games, the gap with China is growing, and expected mobile game market share dropped from 14.1 percent in 2015 to 8.2 percent in 2016. As such, growth has been slowed down and competition in the global market has become increasingly fierce. The Korean game industry, in particular, accounts for 46.3 percent of mobile games and 49.7 percent of PC online games in the entire domestic game market, and is limited to only two game platforms. The genre of game is also focused only on the RPG (role-playing game) genre. Especially, in recent years, the proportion of mobile game releases using the intellectual property (IP) of popular old games in the genre of MMORPG (Massive Multiplayer Online Role Playing Game) has been increasing. What is important here is that the precarity in the Korean game industry is related to the rapidly increasing mobile game production system.

Since around the 2010s, the game production has started to take place mainly on mobile platforms, which are based on a business model that sells opportunities for "obtaining game items" based on probability. On the other hand, "action games" based on the Playstation console platform or adventure games for PC have been produced in relatively fewer numbers. How did this sudden change into mobile platform and game standardization happen? One of the main reasons is that PC online games, which accounted for the majority of the Korean game market, have been losing popularity. The first reason is that the smartphone market has expanded in Korea after the 2010 s since the App store and Google Play mobile market officially opened in Korea. As a result, more and more companies have started to make mobile games. Secondly, since 2011, the "game shutdown policy" has been implemented to restrict the use of PC online games at nighttime for under sixteen-year-olds in Korea. In this context, game companies gradually started to turn their focus toward mobile games and gradually left PC platforms.

However, the competition in the mobile market was highly intense, and smallsized game companies had to share 30 percent of their revenue with Apple or Google Market and with publisher contracts, resulting in an uneven ratio of the revenue of the publisher and the development team: about $6: 4$ or 7:3. The situation 
was compounded for smaller Korean game companies as the games developed in China and other countries became more competitive in the global market. In this process, large game companies and publishers, such as Netmarble, have become more influential in the business by merging and acquiring small development teams. By the time the Korean game industry established a profitable formula of similar games that could be massively produced, a particular pattern of game production was coalesced into a standardized practice. Participants in this study also testified about this situation.

Overall, there is an overwhelming feeling that the atmosphere is very depressed. The market is too focused on mobile, and the diversification of the market is still not working. I think there should be more games of different platforms and genres. (Kim, C. K., $3 \mathrm{D}$ graphic artist)

In terms of play style, user interface (UI) system, and business model, following and copying the success model of $<$ Lineage 2 Revolution $>$ [which is produced by Netmarble] is inevitable. (Jang, M. I., Client Programmer)

This was a sign that the diversity of the game was lost as the business model started to decide and determine the game content. In this process, a few number of users who spent a lot of money on games have occupied dominant portion of sales, and the game companies tried to make games only to satisfy those certain users, which affected not only the majority of ordinary game users but also the developers who lost pride in their games. The bigger problem was that this change had a huge impact on the working environment of game developers in a negative way.

As the major game platform changed from PC online to mobile, the trend in mobile game genre also have transitioned into large MMORPG games. However, the development cycle is getting even shorter and the competition for speed is accelerating. Game production methods and systems have changed from traditional waterfall development methods to more rapid, experimental, and agile development methods. And they have to provide updates more frequently. In this situation, game companies have chosen to exploit game workers so that they can reduce production costs and sustain their business. As a result, the crunch mode became more frequent and developers lost autonomy and creativity over their labor process. As the division of labor is deepened and repetitive tasks were assigned, the game developers were faced with the problem of de-skilling, like labor on a conveyor belt. The story can be summarized as below in figure 2 . 


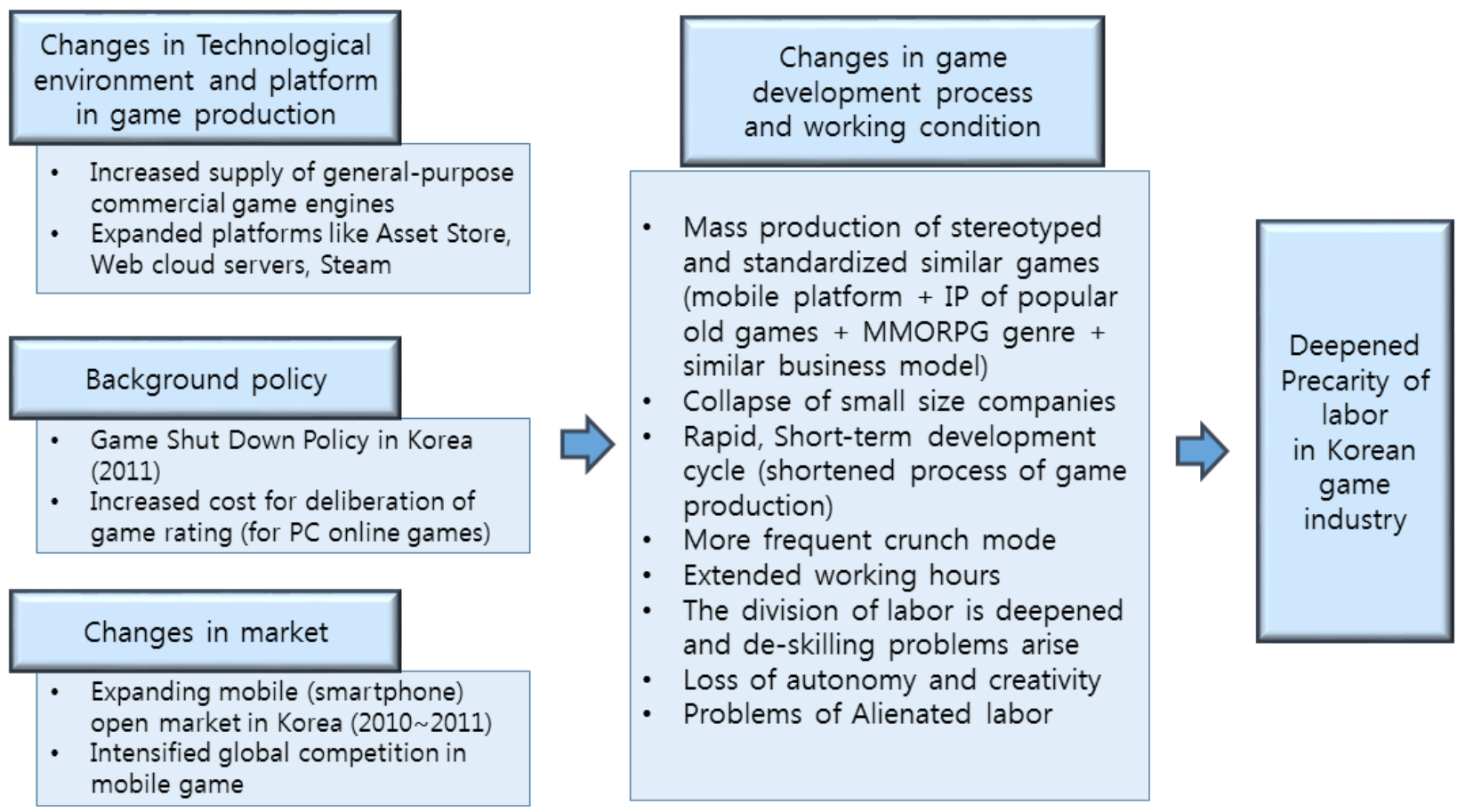

Figure 2. Changing Environment of Game Production and Deepened Precarity in Labor

\section{B. Deepened Precarity of Korean Game Developers}

How has the precarity of game developers been deepened in this context? The precarity of game developers can be analyzed by dividing them into the problems of (1) employment and career, (2) wage and income, (3) collapse of work-life balance, (4) de-skilling and alienated labor.

\section{Precarity of Employment and Career}

Labor in the game industry is very flexible. Recruiting and dispersing workers on a project-by-project basis is very common. Besides, there is a common perception that if a project is terminated, developers should leave the company or the project team. In the past PC games era, generally, games were developed for three to five years or more, and once developers got a job, they could work for a long time. However, in mobile game projects today, the life-cycle of game studios and production teams has seriously shortened. Thus, the problem of employment instability is getting worse. According to a survey conducted with over 621 game 
developers in 2017 (Gurogu Worker's Welfare Center, Report on Worker, Working Condition and Health in Game Industy), 48.5 percent of the respondents did not specify the duration of the contract, 33.1 percent thought that they should leave the company when salary negotiation breaks down, and 43.1 percent said that they must leave when the team is dismantled. Also, more than 62.6 percent of the respondents predicted that the future will not change regardless of the success of the project they participated. 72.1 percent thought that they would not work until they are over sixty years old (Gurogu Workers Welfare Center 2-16). As we can see here, many of game developers are experiencing job insecurity and have a negative perception of continuing their careers.

The problem is that there is no definite answer to solve this precarious condition. Then why do they not resist and raise their voice strongly? There are several reasons they could not do it. First, the network of social relations around the game industry is very small, especially in Korea. Once the relationship with the superior members of the company gets unpleasant, they carry the risk of being stigmatized as a "difficult person to work with," which would negatively influence their future job opportunities.

People are very naïve in this business. So if they are asked to leave the company, they just leave. Because personal relation and network is very important in this business, people try not to leave bad impressions to the managers and don't want to fight against them. Because the managers are almost all connected with other managers, they check whether the developer is docile or rebelling. (Kim H. S., game designer)

The second reasons why the workers could not effectively resist was that the developers are usually not aware of the way to protect their right as workers and they are not collectively organized well. Generally, for game workers, it is widely accepted as a protocol to leave a job when the project is over. Furthermore, the salary negotiations are made not at a level of an organized group but at an individual

level of the person-company relationship, which mostly makes the developers very vulnerable.

\section{Precarity of Wage and Income}

Most game developers in Korea are subject to the "comprehensive wage system." It is a form of contract that predicts overtime work hours to be added to the basic wage, to pay slightly higher wages. The problem is that developers usually are paid less than their actual working hours. Start-ups and small-sized companies, except for big names, are often unable to pay their developers on time, so payouts 
are frequently delayed for months or even a year. In that case, game developers must solve their livelihoods through side jobs. This clearly demonstrates that contractual processes are very disadvantageous to developers in the game industry, and responsibility for solving this problem has been given only to the developers themselves. In Korea, the income gap among the developers largely depend on the size of their company, discipline, and their years in business, and many young developers receive salaries of about 1-1.5 million won (about US\$ 930-1400). In addition, female developers were found to receive less wages. 58.7 percent of women reported monthly salary less than 3 million won, compared to 45.2 percent of men (Gurogu Worker's Welfare Center 5-7).

\section{Sophisticated Exploitation: The Collapse of Work-life Balance}

As many previous studies have addressed the problem of crunch mode labor, there is a problem in the Korean game industry that the balance of work and life collapses due to sophisticated and elaborated labor exploitation. Especially, since 2017, the Korean game industry has gained public attention for game workers who committed suicides due to intolerable and extreme stress and for those who had serious health problems due to overwork. According to a survey results cited above, it was found that game developers worked 14.4 hours a day during the crunch mode and 84.2 percent of them have experienced that. Moreover, 87.6 percent of the respondents said that they have stayed at the company for twelve hours or more over the past year, 39.6 percent said they stayed longer than twenty-four hours, 17.9 percent of them answered they stayed over thirty-six hours.

In the Korean game industry, it is often said that they "make a game by 'grinding' developers". In most game companies the researcher visited, the official work hours are from 9:30 am to 6:30 pm. However, during the crunch mode, they are required to work until late at night constantly.

They (the companies) don't care about our personal life or anything like that, using people's time and passion only for the success of this project. I think that's a serious problem. (Lee, I. J. Client Programmer)

Among the developers who participated in this research, many were suffering from health problems. Fifteen-year-career game designer Soh could only sleep for two or three hours a day for more than a month. Consequently, he had a pulmonary embolism and had been taken to an emergency room. A ten-year-career game designer, Song, had only five days off work in a year and fell down with arrhythmia. "I felt the fear of death," he said. As such, game workers suffer from physical illnesses 
such as back, neck, and wrist problems due to generalized excessive labor, or suffer psychological diseases such as insomnia or depression. The crunch mode labor practice is not just a side effect of being tired and stressed because of the long working hours. Overall, it breaks the mental and physical health of developers and undermines the balance of daily lives of developers.

\section{The Problem of Alienated Labor}

Precarity is also deepened by alienated labor. This tendency is even more serious in the context of large-scale production of monolithic games that combine RPG genres with specific business models, centered on mobile platforms as discussed earlier. Developers must design and develop games that are tailored to the concept, play system, and business model of the game set by the leader of the company or managers. In this situation, it becomes harder for developers to insist their original ideas or opinions on the game, while the influence of the marketing and business department becomes dominant. Therefore, developers are likely to be distanced from the product they are producing. Traditionally, game developers have been proud of their self-esteem, craftsmanship, and creativity as they were allowed to follow their original ideas, but the identity and pride as a developer are diminishing.

Another problem is de-skilling. In the past, game development had to start from making a fundamental base system and in-house engine. However, in recent years, many new software and commercial game engines were developed so that they can replace professional technicians, giving emergence to a working culture that does not consider the technical skills and expertise of the developers as important. In this situation, game developers are becoming increasingly difficult to accumulate technical know-how and skills. In particular, young developers who have recently gotten the job are not getting the opportunity to understand the whole process of game production, they are just simply taking on repetitive, fragmented tasks.

I want to do character illustrations, but I can't concentrate on it and just keep taking UI [user interface]-related work that anyone can do. I have to take a lot of rolls to get a job and to make money. It is difficult to learn how to make a game as a whole because I'm only doing such a detailed split. In the course of my work, I feel like I'm a part of the machine. (Suh, J, H. 2D artist) 


\section{Various Aspects and Differences of Precarity in Hierarchical Structure}

The degree and nature of the precarity experienced by individual game developers are quite variegated. It depends very much on how large the team they are affiliated with, or which discipline they belong to (designer, artist, programmer, QA, etc.) and how long they have worked in the industry. Also, depending on whether they are male or female, precarity experiences vary.

For example, people who are generally part of a small development team become more and more unstable in terms of employment, career, and income. In addition, artists and designers are more unstable compared to programmers because programmers are recognized as technicians with more specialized skills, whereas artists and designers tend to be seen as easily replaceable. Also, the Korean game industry tends not to hire new developers in recent years. Rather than providing systemic training to nurture young developers, they prefer to recruit experienced workers who can perform their tasks immediately. As a result, younger developers are gradually losing their ground. Those who had a dream of self-realization and entered into the field because of the pleasure of making games, should endure such a great despair. On the other hand, older developers who are above forty years of age are also concerned about how long their career can last.

Finally, there are also gender differences. In general, female developers are subject to tacit discrimination in a male-oriented workplace culture, and such discriminatory cultures act like a barrier for them to continue their career as a developer. Not only that, such practices also make women feel skeptical, frustrated, and alienated about their work.

\section{Characteristics of Deepened Precarity}

What are the main characteristics of precarity in labor? After analyzing data from interview and participant observation, it can be summarized as Figure 3.

The problem of precarity and sophisticated and hyper-exploitative system related to labor flexibility, is overlapped and combined with the problem of alienated labor due to division and de-skilling in labor such as factory labor in traditional industrial era. The creative industries have problems such as high risk, unstable employment, and advanced exploitation, but in return, the workers can pursue autonomy, creativity, expertise and have the advantage of self-realization through labor. On the other hand, in the case of manufacturing, there was a problem of alienation and de-skilling. But as a reward, it offers opportunities and advantages of getting 


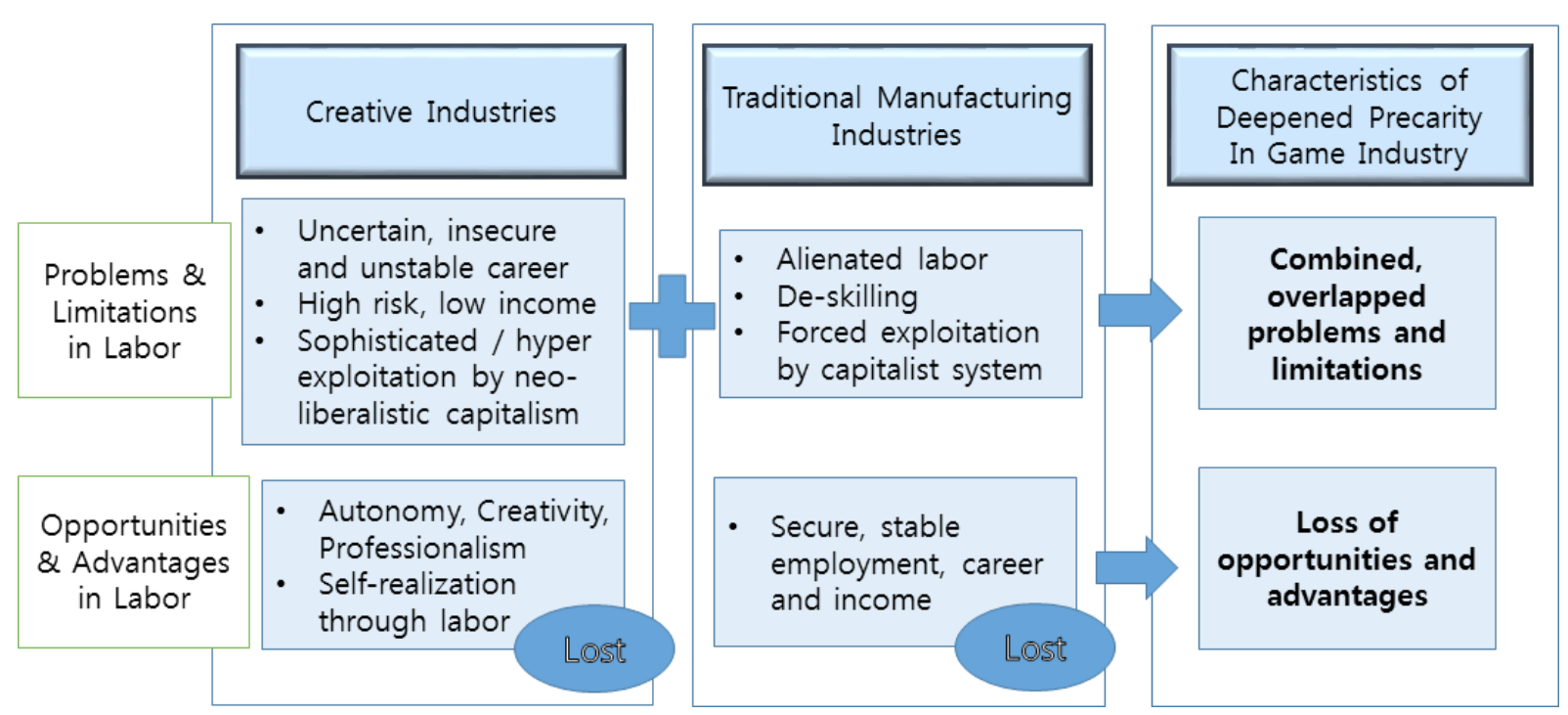

Figure 3. Structure of Deepened Precarity in the Korean Game Industry

a secure job and stable income. The critical feature of deepening precarity is that while the problems and limitations are combined and overlapped, the opportunities and advantages are lost. In other words, it could be said that while the problems of labor precarity in the creative industries and traditional manufacturing industries are combined and thus amplified, the stability and advantages that the previous form of labor once guaranteed vanish.

In particular, the loss of meaning in labor and loss of opportunities that provide self-realization through autonomy, creativity, professionalism in labor are becoming a huge threat to game developers, who voluntarily endure the risk of structural instability and labor flexibility. They are losing the value of the labor itself.

\section{HOW DIGITAL CREATIVE WORKERS CAN OVERCOME PRECARITY: POTENTIALITIES OF CONVERGED WORK AND NETWORKED CREATIVE COLLABORATION}

Are there any possibilities or ways to overcome the hardships of game developers so far? This section analyzes the unique competence and potential of Korean game developers in the labor process, utilizing the concept of digital creative labor proposed in the theoretical discussion. Through this, we can examine the practical possibility of overcoming the precarious conditions autonomously and innovatively. 


\section{A. Opportunities of Technological Environment}

The evolution of software tools and the dissemination of commercial game engines, and a series of major changes open up new possibilities. For example, various platforms, which have decisive effects on the production, distribution and consumption of game, are technically evolving. In particular, commercial game engines such as Unity and Unreal are distributed at a very cheap price, even free to amateur developers. They are characterized by improved work efficiency, multiplatform support, and enhanced collaboration utility among developers. These changes are making it easier for a small development team or a single developer to create games without the need for specialized expertise. The evolution of the game engine has enabled the rapid development process and testing of prototypes, especially in a way of convergence of media technologies, making game design, art, and programming integrated through the engine.

Developers who participated in this study were also actively utilizing the functions of these engines and positively evaluated their potential. They also take advantage of testing features for games offered by Google Market or they can use the online asset store to purchase graphic resources for the game. They also have the opportunity to promote their games by communicating with users via SNS or online communities. Sometimes they could find fellow developers and build a new team through online communities or SNS. In this process, small development teams are more likely to use the opportunities offered by these digital environments to support their marketing, distribution and services, and also to acquire resources through crowdfunding.

This means that various methods of convergence are possible in the production process these days. For example, with the increased information flows, there are more chances to collaborate among different developers. As the possibilities of collective intelligence and participatory culture have grown, game developers are connected with each other through utilizing media and technology environments. Multiple steps of work processes are merged within a single developer. Based on this technological environment, game developers could be able to do digital creative work and it could become a valuable resource to overcome their precarity. 


\section{B. From "Fragmented Labor" to "Converged Work"}

How could the potentiality of digital creative work be realized in the working process? The subjects of digital creative work do not just complete a given task, but perform a multiple "work" by combining necessary competencies and integrating all of the orders and stages of work. The whole working processes can be integrated on their own autonomous, multiple work using various software tools and network resources. This "converged work" shows the potential to overcome the problem of de-skilling caused by division of labor.

Nowadays, in indie games, it's common that single person is responsible for many areas of work. And the level of know-how and craftsmanship gained from experience of the game development is much higher than before. Indie game developers must be capable of doing UI design, illustration, $3 \mathrm{D}$ graphics, programming, and more. So I think that even though the depth of specialty for a specific field is shallow, they can get more other generalist capacities instead. Even if they lack expertise in a specific area, they can build a successful game, publish it in the market, and communicate with users to enhance people's insight into the game. So I think the advantage of indie developers is the ability to understand cultural trends, the ability to communicate with users, and the versatility to perform multiple roles simultaneously. (Kim, D. K. indie game programmer/ designer)

In particular, small-scale development organizations and single person indie developers have learned the new technologies for game development and acquired the know-how related to development by using various networks and resources. For example, it is possible to perform a self-directed "converged work" without simply repeating a specific task given in a fragmented state. Furthermore, by accumulating collaborative experiences with other colleagues, they could become "multi-skilled," crossing the boundaries of disciplines as artists, programmers, designers, or even as businessmen. They find business know-how that cannot be learned from the established institution of the game industry or senior developers, and they could be commercially successful and well-appreciated through creative planning skills that distinguish themselves from others. It could demonstrate their unique competency as digital creative workers. The combination of enthusiasm for the game and the ideals and dreams of a game developer drove forward the ongoing process of their precarious career.

However, there are many limitations to completely overcome precarity if the workers are in the state of isolation. That is because it can lead them to self-exploitation through instrumentalization of passion. Therefore, in order to overcome precarity, they should not only pursue individual success but also 
construct a rich social relationship through solidarity and joint action with fellow developers.

\section{Networked Creative Collaboration}

Game developers can go beyond putting efforts individually and actively form networks with other developers to make spaces of collaboration with one another. For example, they can use SNS to share their group's activity and information related to employment and know-hows on game development. They can also empathize with each other, talking about the difficulties and emotional suffering they have in their careers. For example, the online community of Indie Game Developer's Shelter, DevRookie, or Indie Game Developer Group and Smartphone Game Developer Group on Facebook are representative network of developers. In Korea, The Guild of Game Developers has been actively promoting legislative activities to protect the right of developers since its foundation in 2013. They conducted surveys to improve illegal wage and overtime working in the game industry. Four of the developers who participated in this study are members of this group and they are struggling to improve the working condition in the game industry by raising critical awareness on endemic problems across the game industry with other peers.

These efforts to challenge the existing game production practices and organizational culture could be organized into creating an alternative working culture. As a female game designer and company representative, Lee is making games especially for female users. She is trying to build a female-centered game production and game play culture that is distinct from the male-centered ones, which tend to be aggressive and violent.

The feminine gaming culture is a culture that helps each other in a coherent community rather than defeating others. We seek emotional stability and empathy rather than efficiency and profitability. I am receiving encouragement and appreciation from users all over the world for the women-centered games we make. Beyond merely pursuing commercial success, we donate together and make a secondary creative work such as fanfic, fan arts. (Lee, S. J. CEO/ designer of small sized game company)

As the network of game developers expands, a collaborative network with game users could be formed in a broader scale. In particular, collaboration with users is based on shared cultural experiences of the game. According to a study by O'Donnell, there are linguistic and cultural codes that are common among developers at work places. It can also be formed in relation with users. A variety

of game-related secondary creations and derivatives can be produced within a 
broader network of collaborators, including developers and users, such as Korean online game boards Ruli Web and Inven. For example, in the community bulletin board, user-created contents such as game play videos, parody, fan art, jokes and cosplay photos are shared, which constitute a form of "game subculture." The game subculture formed and enhanced here serves as a bridge between developers and users, especially hardcore gamers and the people who are big fans of their favorite games. It not only strengthens the unique cultural identity of game developers, but it is also a cultural resource that enables game users to participate in the field. The pictures in figure 4 are images showing fan art and costume play performance of users inspired by Korean famous mobile game Crusaders Quest.

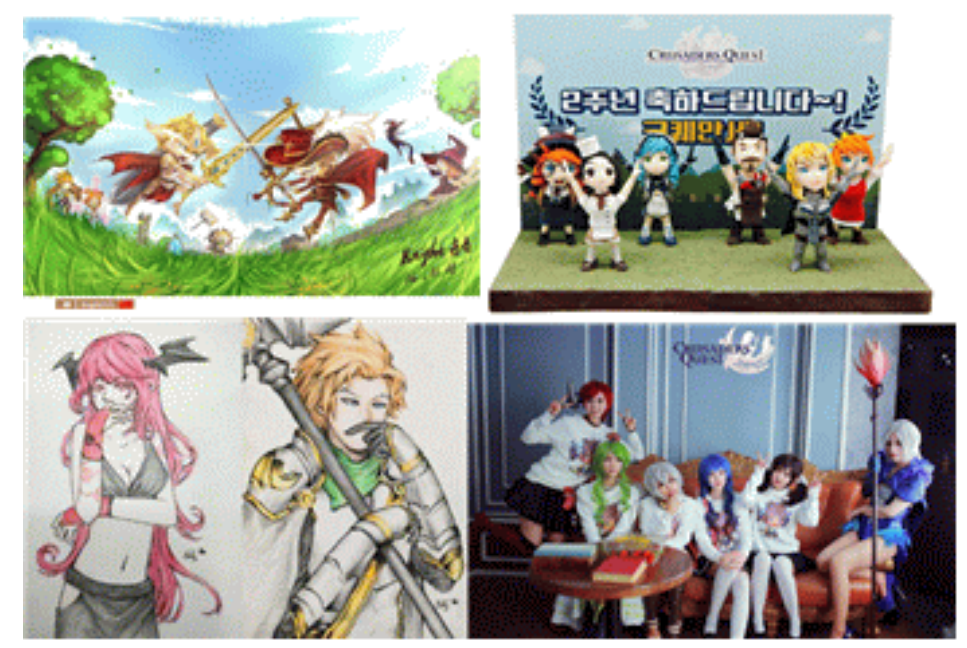

Figure 4. Crusaders Quest User Fan Art and Costume Play

These secondary creations by users send strong signals to developers that their games are widely beloved and that they have a strong cultural influence. Developers can feel the pride and reward of their work while watching the responses and activities of these users. If the network of developers we discussed earlier could be a forum for sharing information about career development and expertise of individual developers, interaction with users will be meaningful as a process of reconfirming the social and cultural value of their work.

As such, game developers and users interact through game subcultures by coproducing the game in a broad sense, which could be understood as a "networked creative collaboration" in this study. For example, the members of the game subculture are not just passive game consumers. They pay attention to and actively 
pursue essential fun, unique elements and artistry of the game. Therefore, they are well informed about the problems in the contemporary game industry, such as monopolized platform, genre problem, business model, billing problem, and they even criticize the established game companies. Sometimes, members of this subculture are recruited by the companies that produced their favorite game. In the case of the Crusaders Quest development team, two core 2D artists are from the famous fan art community. Also, Ji, a single developer who created the indie game cartoon 999, has been actively involved in the co-production process with his fans. He explained that "if a developer works in an indie game market, the relationship with the user should be much more special."

Game subculture communities can be viewed as communities of "game production culture" in a broad sense. This process could be understood as the progress from labor to work, from personalized and fragmented labor to converged and collaborative work. Game subculture communities and networks have become a domain for discussing, reflecting, and criticizing the Korean game industry on which critical issues regarding the working condition of game developers are shared. In these communities, game developers will no longer feel a sense of discomfort to produce "harmful addictive substances," but will be more reflective about their works. The most important thing is that with networked creative collaboration, it becomes possible to produce games based on collective, communal, and collaborative creativity. Ultimately, this kind of creativity and solidarity is necessary to overcome precarity.

\section{CONCLUSION: CULTURAL PRACTICE AND POLICY STRATEGIES FOR SUSTAINABLE GAME INDUSTRY ECOSYSTEM}

So far, this study analyzed how the precarity of Korean game developers has been aggravated and discussed the possible ways of challenging the structural constraints. To this end, we reviewed the structural changes of the Korean game industry since 2010. Changes around the game industry caused rapid transitions to the mobile platform, resulting in deteriorating working conditions. And the working process of game production was reduced into a simple, repetitive, and laborious series of tasks. Game developers were experiencing precarity in employment, career, and income. Their balance of work and life collapsed due to the enhanced exploitation of labor and they suffered health problems. Above all, the workers were deprived of their autonomy and creativity and had to endure de-skilling and excessive labor exploitations that once existed in the traditional manufacturing era. Eventually, the condition of precarity has been complicated as it combined the downsides of both creative and traditional industry. 
Then how can game developers as digital creative workers overcome these structural limitations? The possibilities and potentials were explored through the concept of digital creative labor. The study noted that the experience of digital creative labor in particular has created a unique competency for game developers, which is achieved through the practice of convergent work and networked creative collaboration that takes advantage of the technological environment. For example, by turning fragmented, individualized, and alienating labor into convergent work, they can restore autonomy and pursue multiple skills in new ways. Through networking and maintaining solidarity with fellow developers, they can make demands for a stable working environment and produce reflective game discourses with members including users in the game subculture community, in the hopes of exploring alternative ways to develop the game industry.

Is that enough? Actually it is not. As we can see from previous studies (DyerWitheford and de Peuter; Teipen; Legault and Weststar; Thompson et al.), realworld game developers are working in an unorganized, personalized, fragmented form. In this working condition of the game industry, they are more likely to perform a given task repeatedly, without changing the underlying conditions that lead to sophisticated exploitation and alienated labor. In other words, the capacity of the game developers and their efforts alone cannot solve the structural problems that they are in.

Ultimately, two tracks of strategy are needed at the same time. On the one hand, the game developers should obtain their autonomy and independence through cultural practices reinforcing their creative competencies. On the other hand, institutional, legal improvements, and policy measures are needed to support them to reduce their precarity. The first strategy is to continue cultural and organizational practices to strengthen the unique competencies of developers as a digital worker, as discussed in section 4 above. However, it is difficult to improve the environment of game labor only by “possibilities" or "potentials." Game developers' technological and cultural capacities should be channeled into more powerful organization, solidarity, and practices to improve the troubled manufacturing systems of game industry.

The second strategy is to improve the poor working conditions of creative industries through institutional, legal interventions and actions in policies. This also aims to provide practical support for digital creative workers. Specific measures can be made by referring to existing studies and reports on the improvement of labor environment and treatment of cultural industry workers or artists (Lee et al.; Kwon and Kwon; Lee). This is also what most of the interviewees are asking for. 
This strategy can be performed in two directions. First, it could be conducted in a way of protecting the rights and interests of game developers. For example, social insurance, such as employment insurance and industrial accident insurance, can be applied to as many game developers as possible, thereby building and strengthening social safety nets. Recently, the Korean government announced the introduction of "Korean-style employment insurance for artists" to strengthen the welfare of artists, and declared the necessity of protection for freelance artists' rights (Seo). This legal and institutional improvement is also needed in the game industry. It is also necessary to use standard contract forms to achieve fairness in employment negotiations, and to take measures to solve the problems of the comprehensive wage system and to ensure the appropriate level of wages. Furthermore, it is also essential to establish legal and institutional grounds for more strictly regulating and controlling illegal overtime, labor exploitation, and delayed payment of wages.

Second, it could be done by making policies for game developers to support innovative game production based on autonomy and creativity. This could be the kind of a policy that helps them to empower themselves. To do this, young developers should be provided with education on technical knowledge such as new platforms, engine and software for game production, as well as consulting for start-ups and space for work. It is also important to enhance networking so that they can exchange important information and know-how among developers. Therefore, it is necessary to provide opportunities for them to exchange and gather together through various seminars, conferences, and game shows. In addition, support for distributing and publishing, as well as incubating and facilitating the small companies in launching their games into the global market, and mentoring systems should be increased.

The important thing is that both strategies of cultural practices and policy measures should be pursued at the same time. If we emphasize cultural practices alone, their practice can be a reckless and void attempt without substantial institutional support, and unstable working conditions would hardly be improved. What if there is only institutional and policy strategy with no cultural practice? Since the game industry is based on autonomous cultures and innovative capacities of developers, it is very important that the labor ethics, culture, values and meaning of their work should be formed and confirmed by the workers themselves. If there are only laws, institutions, policies on game industry without subcultural communities of workers, users and fans or their voluntary cultural practices, they will lose the meaning and value of the work itself. It is only through their own practice that they can improve old production practices and restore creativity and autonomy.

The ultimate goal of these strategies is to reduce the labor precarity of game developers, while maximizing their creative and autonomous competencies. 
Furthermore, these strategies will create a more stable and innovative game production environment and culture. This allows developers to gain greater autonomy and independence, expand collaboration networks, and strengthen negotiating power in a more organized fashion. This will ultimately lead to the sustainable development of the game industry ecosystem.

What is the significance and implications of this study? Firstly, by conducting a case study in the game industry, it critically explained the problem of a labor environment in detail, which is an important issue in the whole creative industry these days. More specifically, it analyzed the factors that deepen the precarity of digital creative workers, considering the context of the Korean game industry. Through in-depth interviews and observations of game developers, we can see how precarity in their labor process is specifically experienced. In other words, it is the greatest contribution of this study to reveal in detail the nature and concrete aspects of precarity. The second implication of this study is that it has provided strategies to actualize the positive possibility of digital creative work by easing the precarity of game workers and strengthening their unique competencies. Especially, it was confirmed that the multifaceted practice is needed because the problem of precarity cannot be solved only by institutional support or expectation on cultural potential. This could be a reference for establishing the purpose and strategy of policies to support the Korean game industry. However, the specific methodologies of the strategy could not be fully presented in this paper. More detailed follow-up studies should be conducted. In addition, this study on work in the game industry needs to be extended to research on other creative industrial workers such as film, $\mathrm{TV}$, and animation. 


\section{Notes}

1. According to Butler, the concept of the precarious could be divided into "precariousness" and "Precarity" Precariousness refers to the existential instability and weakness that any person has, a concept that shows how human beings are inherently dependent on the social relationship with others. On the other hand, precarity is related to differentiation and "othering" of resources and power allocation, and it can be seen as a dimension of social structural inequality and discrimination. This study focuses on the concept of "precarity" and attempts to explore the problem of game industry labor by elaborating the concept further.

2. Sennett argues that ethics of flexible labor in the age of late-capitalism or postFordism interferes with the stability of life and the formation of stable personal career, while it emphasizes the competence of aggressive adaptation to a rapidly changing environment and requires skills of problem-solving, collaboration, and making a good human relationship.

3. Berardi explains this phenomenon as "being forced and exploited to work the soul."

4. They also tend to reject wearing uniforms in workplaces that represent social status, and express liberal, progressive cultural and political tastes and styles. It is also believed that their labor ethics have inherited the culture of the Silicon Valley in the United States, which grew out of counter-culture and youth culture in the 196os. It also implies a unique community culture, such as autonomous labor ethics of hackers who were early Internet and software developers, technical enthusiasts, community culture of web enthusiasts, free sharing and cooperation of information, and criticism of the logic of capitalism and commerciality.

5. Arendt distinguishes labor that is something that people have to do to make a living as a biological entity, and the work as a creative activity. This paper emphasizes the term "work" because it can be seen as an activity not limited to the contractual framework of wage employment relations. Besides, this study considers that "labor" represents industrial workers in the relations of production, class relations, and inequality, while "work" can be a concept that includes creative labor and acting and agency.

6. The information of the participants is categorized as follows. (1) Disciplines: three people in $\mathrm{PD}$, one person in $\mathrm{PM}$, ten people in game design, eight people in art (including TA), seven developers who are responsible for two or more at the same time. (2) Company size: nineteen people in large companies (100 or more employees), eleven of them are in a small and mid-size team, seven of them are in start-ups or single-person developer. (3) Positions: ten managers, ten CEOs including start-up, and twenty-two developers who are employees. (4) The average age of participants: 33.86 year old. (5) Average career: 8.29 years, (6) Gender composition: twenty-nine male, thirteen female. 


\section{Works Cited}

Arakji, Reina Y., and Karl R. Lang. "Digital Consumer Networks and Producer-consumer Collaboration: Innovation and Product Development in the Video Game Industry." Journal of Management Information Systems, vol. 24, no. 2, 2007, pp. 195-219.

Arendt, Hanna. The Human Condition. Translated by J. W. Lee. U of Chicago P, 2017.

Berardi, Franco. The Soul at Work: From Alienation to Autonomy. Semiotxt(e), 2009.

Braverman, Harry. Labor and Monopoly Capital. $25^{\text {th }}$ Anniversary Edition, Monthly Review Press, 1998.

Bulut, Ergin. Creativity and its Discontents: A Case Study of Precarious Labour in the Video Game Industry. Ph.D. Dissertation, University of Illinois at Urbana-Champaign, 2014.

Butler, Judith. Frames of War. Verso, 2009.

Chae, Suk Jin. "Technology, Labour and Precarious Lives - A Theoretical Reflection on the Relation between Immaterial Labour and Precarity." Korean Journal of Communication and Information, vol. 79, 2016, pp. 226-259.

Deuze, Mark. Media Work. Polity, 2007.

Dyer-Witheford, Nick, and Grag de Peuter. Games of Empire: Global Capitalism and Video Games. U of Minnesota P, 2009.

Foucault, Michel. Security, Territory, Population: Lectures at the Collège de France 19771978. Translated by Graham Burchell, Palgrave Macmillan, 2007.

--. The Birth of Biopolitics: Lectures at the Collège de France, 1978-1979. Translated by Graham Burchell, Palgrave Macmillan, 2008.

Fuchs, Christian. Digital Labour and Karl Marx. Routledge, 2014.

--. "Labor in Informational Capitalism and on the Internet." The Information Society, vol. 26, 2010, pp. 179-196.

Fuchs, Christian, and Sebastian Sevignani. "What is Digital Labour? What is Digital Work? What's their Difference? And Why Do These Questions Matter for Understanding Social Media?” Triple C vol. 11, no. 2, 2013, pp. 237-293.

Gurogu Worker's Welfare Center. Report on Worker, Working Condition and Health in Game Industy. Gurogu Worker's Welfare Center, 2017.

Hardt, Michael, and Antonio Negri. Multitude: War and Democracy in the Age of Empire. Penguin, 2004.

Hesmondhalgh, David, and Sarah Baker. Creative Labour: Media Work in Three Cultural Industries. Routledge, 2011.

Jenkins, Henry. Convergence Culture: Where Old and New Media Collide. New York UP, 2006.

Jung, Jun Hee. “The Contrast of the Digital Work of Labor." Digital Society and Communication, edited by the Korean Society for Journalism and Communication (KSJC), Communication Books, 2014, pp. 146-184.

Kerr, Aphra. "The Culture of Gamework." Managing Media Work, Sage, 2011, http:// eprints.maynoothuniversity.ie/2901/. Accessed 2 Aug. 2018. 
KOCAA (Korea Creative Content Agency). Contents Industry Outlook 2018, KOCCA, 2018.

Kwon, Heiwon, and Soonwon Kwon. "Searching for the Possibilities of Collective Representation of Artists and Cultural Workers: Beyond Workplace Unionism." Journal of Social Research, vol. 17, no. 2, 2016, pp. 77-116.

Lazzarato, Maurizio. "Immaterial Labor." Radical Thought in Italy: A Potential Politics, edited by Paolo Virno and Michael Hardt, U of Minnesota P, 1996, pp. 133-150.

Legault, Marie-Josée, and Johana Weststar. "The Capacity for Mobilization in ProjectBased Cultural Work: A Case of the Video Game Industry." Canadian Journal of Communication, vol. 40, no. 2, 2015, pp. 203-221.

Lee, Seung-ryul, Sam-soo Kim, Joon-wook Hwang, Myung-joon Park and Hyun-gu Shin. Freelance Labor and Risks - Policy Tasks for Building a Social Safety Net for Freelancers. Korea Labor Institute, 2013.

Lee, Yong-Kwan. Analysis on Content Field Working Environment in South Korea. Korea Culture and Tourism Institute, 2016.

Lorey, Isabell. State of Insecurity: Government of the Precarious. Translated by Aillen Derieg, Verso, 2015.

O'Donnell, Casey. The Work/Play of the Interactive New Economy: Video Game Development in the United States and India, ProQuest, 2008.

Park, Jin Woo. "Flexibility, Creativity, Precarity: A New Way of Problematisation on the Media Work Research." Media and Society, vol. 19, no. 4, 2011, pp. 41-86.

Peticca-Harris, Amanda, Johanna Weststar, and Steve McKenna. "The Perils of Projectbased Work: Attempting Resistance to Extreme Work Practices in Video Game Development." Organization, vol. 22, no. 4, 2015, pp. 570-587.

Postigo, Hector. "Of Mods and Modders: Chasing Down the Value of Fan-Based Digital Game Modifications." Games and Culture, vol. 2, no. 4, 2007, pp. 300-313.

Ross, Andrew. No-collar: The Humane Workplace and its Hidden Costs. Temple UP, 2003.

Sennett, Richard. The Culture of New Capitalism. Yale UP, 2006.

Seo, Woo-suk. "Understanding Employment Insurance for Artists." Webzine of Culture Tourism, www.kcti.re.kr/webzine2/webzineView.action?issue_count=86\&menu_ seq=5\&board_seq=1. Accessed 1 Aug. 2018.

Scholz, Trevor. "Why Does Digital Labor Matter Now?" Digital Labor: The Internet as Playground and Factory, edited by Trevor Scholz, Routledge, 2013, pp. 1-10.

Teipen, Christina. "Work and Employment in Creative Industries: The Video Games Industry in Germany, Sweden and Poland." Economic and Industrial Democracy, vol. 29, no. 3, 2008, pp. 309-335.

Terranova, Tiziana. "Free Labor: Producing Culture for the Digital Economy." Social Text, vol. 18, no. 2, pp. 33-58.

Thompson, Paul, Rachel Parker, and Stephen Cox. "Interrogating Creative Theory and Creative Work: Inside the Games Studio.” Sociology, vol. 50, no. 2, 2015, pp. 316-332. 